San Jose State University

SJSU ScholarWorks

Master's Theses

Master's Theses and Graduate Research

1990

\title{
Study to estimate the content validity and reliability of a quality of life questionnaire designed for hypertentive patients
}

Carla Botelho Sottovia

San Jose State University

Follow this and additional works at: https://scholarworks.sjsu.edu/etd_theses

\section{Recommended Citation}

Sottovia, Carla Botelho, "Study to estimate the content validity and reliability of a quality of life questionnaire designed for hypertentive patients" (1990). Master's Theses. 74.

DOI: https://doi.org/10.31979/etd.er2w-7sw5

https://scholarworks.sjsu.edu/etd_theses/74

This Thesis is brought to you for free and open access by the Master's Theses and Graduate Research at SJSU ScholarWorks. It has been accepted for inclusion in Master's Theses by an authorized administrator of SJSU ScholarWorks. For more information, please contact scholarworks@sjsu.edu. 


\section{INFORMATION TO USERS}

The most advanced technology has been used to photograph and reproduce this manuscript from the microfilm master. UMI films the text directly from the original or copy submitted. Thus, some thesis and dissertation copies are in typewriter face, while others may be from any type of computer printer.

The quality of this reproduction is dependent upon the quality of the copy submitted. Broken or indistinct print, colored or poor quality illustrations and photographs, print bleedthrough, substandard margins, and improper alignment can adversely affect reproduction.

In the unlikely event that the author did not send UMI a complete manuscript and there are missing pages, these will be noted. Also, if unauthorized copyright materiai had to be removed, a note will indicate the deletion.

Oversize materials (e.g., maps, drawings, charts) are reproduced by sectioning the original, beginning at the upper left-hand corner and continuing from left to right in equal sections with small overlaps. Each original is also photographed in one exposure and is included in reduced form at the back of the book.

Photographs included in the original manuscript have been reproduced xerographically in this copy. Higher quality $6^{\prime \prime} \times 9^{\prime \prime}$ black and white photographic prints are available for any photographs or illustrations appearing in this copy for an additional charge. Contact UMI directly to order.

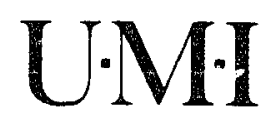

University Microfilms International

A Bell \& Howell Information Company

300 North Zeeb Road, Ann Arbor, MI 48106-1346 USA

313/761-4700 800/521-0600 

Order Number 1342736

Study to estimate the content validity and reliability of a quality of life questionnaire designed for hypertensive patients

Sottovia, Carla Botelho, M.A.

San Jose State University, 1990

$\mathrm{U} \cdot \mathrm{M} \cdot \mathrm{I}$

300 N. Zeeb Rd.

Ann Arbor, MI 48106 


\title{
Study to Estimate the content Validity and Reliability of a quality of Life questionnaire Designed for Hypertensive Patients
}

\author{
A Thesis \\ Presented to \\ the Faculty of the Department of \\ Human Performance \\ San Jose State University
}

In Partial Fulfillment

of the Requirements for the Degree

Masters of Arts

by

Carla Botelho Sottovia

December 1990 
APROVED FOR THE DEPARTAMIENT OF HUMAN PERFORMANCE

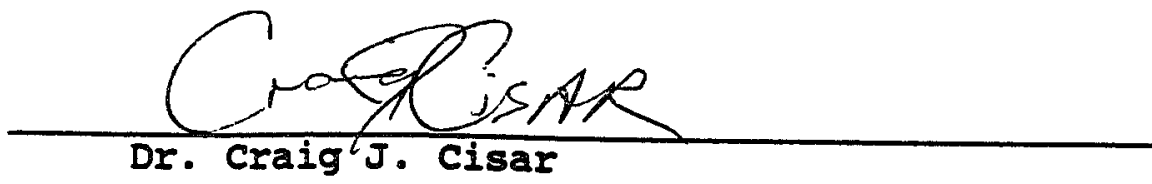

Qi. Leufeest

Dr. Bethany skifflet

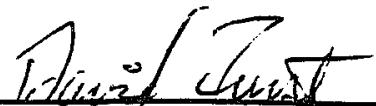

Dr. David Furst

\section{APPROVED FOR THE UNIVERSITY}

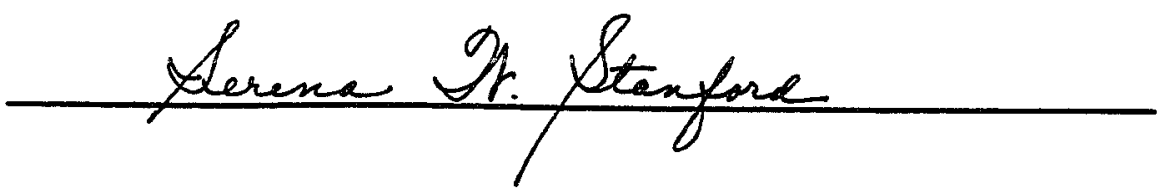




\begin{abstract}
STUDY TO ESTIMATE THE CONTENT VALIDITY AND

RELIABIIITY OF A QUALITY OF LIFE QUESTIONNAIRE

DESIGNED FOR HYPERTENSIVE PATIENTS

by Carla B. Sottovia
\end{abstract}

This study tested the content validity and reliability on a new quality of life questionnaire. Thirty-nine hypertensive male patients ranging in age from 31-59 years were used as subjects. First, 20 experts evaluated the questionnaire for its content validity. They classified each question in one of the three domains of the guality of life spectrum: function, perception, and symptorm. Factor analysis was used to further tort the content validity of the questionnalre. The overall content validity of the questionnaire was poor. Several questions showed ambiguity in their Interpretation and hence, should be reworded. Secondly, the gusstionsaire was given to each pationt. Internal consiatency (reliability) of the guestionnaire was determined from the calculation of alpha coessicients on the grestion ralatad to each factor. The result of coefficient alpha analysis indicated high reliability for factors I, $I I$, and $V(R=.93, .8 I$, and .76 , respectively). It was concluded that this guestionnaire needed to be further retested before used in clinical trials. 


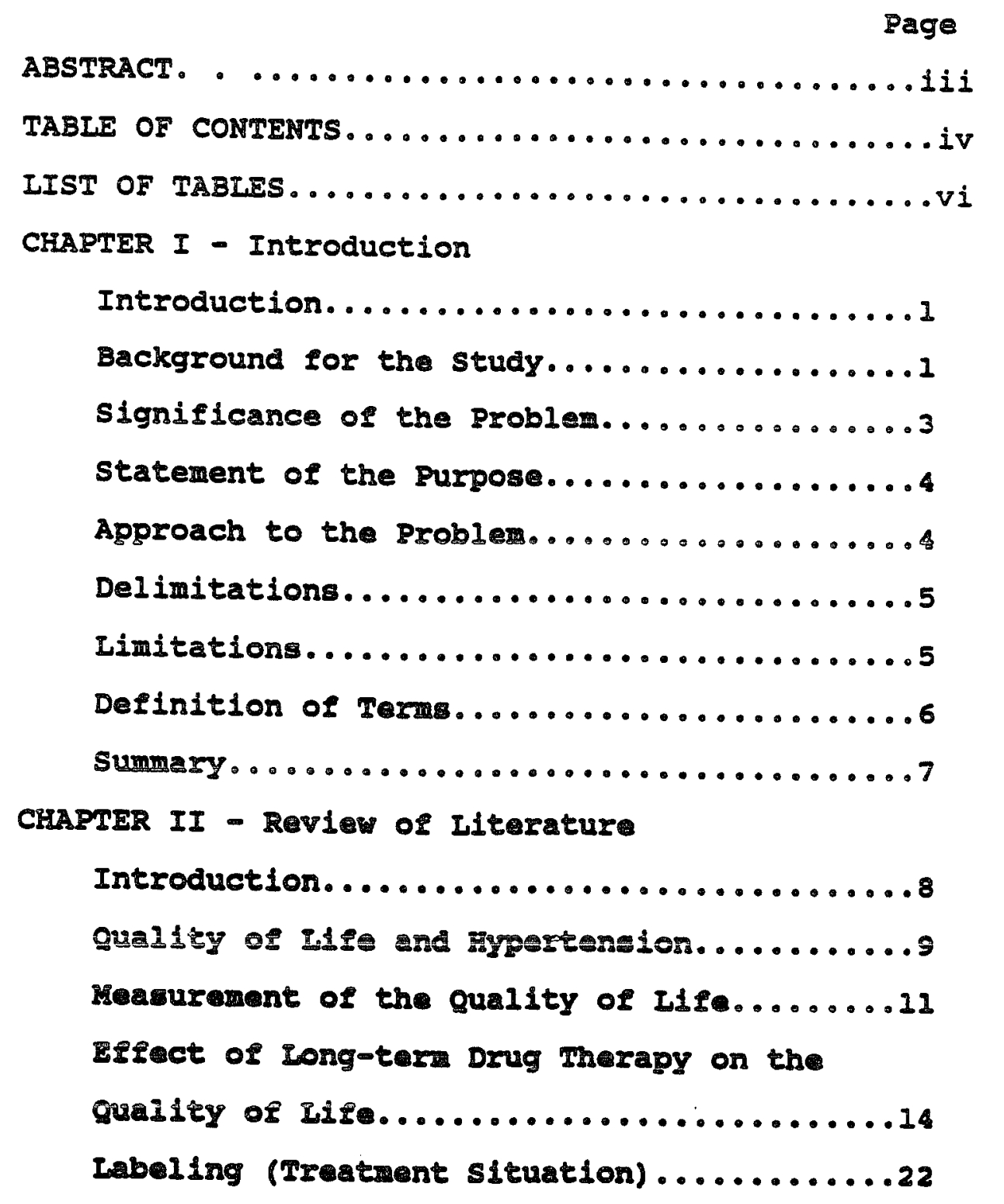


TABLE OF CONTENTS

Page

sumary...........................27

CHAPTER III - Methods

Introduction......................28

subjects.........................28

Instrument. .......................29

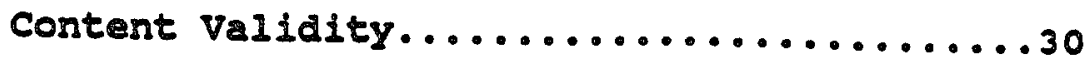

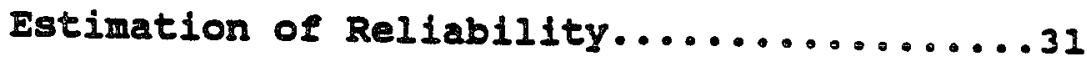

Physiological Parameters...................

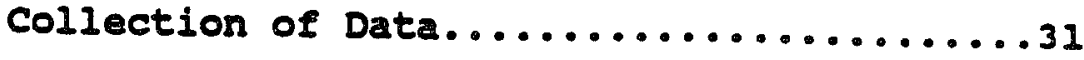

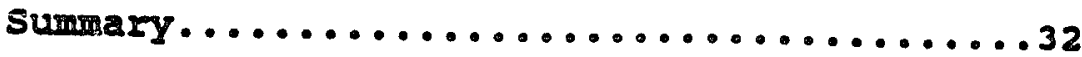

CHAPTER IV - RQSUIE

Introduction. . . . . . . . . . . . . . . . . .34

Analysis of Data..................... 34

Summary of Findings................48

Discussion of Findings...............50

Conclusions . . . . . . . . . . . . . . . . . . . . 56

Heaknease. of study .................57

Recomendations Sor Future Research.......57

Srmary of chapter..................58

REFERENCES. . . . . . . . . . . . . . . . . . . . . . . 59

APPENDIXES............................65 


\section{IIST OF TABLES}

page

Table 1 Physiological Parameters of subjects..35

Table 2 Descriptive statistics of the

Physiological Parameters of subjects..37

Table 3 Descriptive statistics for the 21

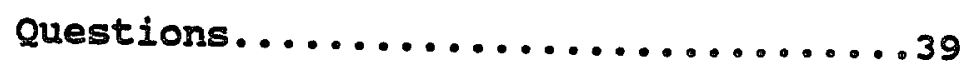

Table 4 Descriptive Responses of subjects.....40

Table 5 content validity.................42

Table 6 Factor Hatrix for the 21 Questions....46 
CHAPTER I

\section{Introduction}

This chapter is divided into the following sections: background for the study, significance of the problem, statement of the purpose, approach to the problem, null hypothesis, delimitations, limitations, operational definitions, and sumary.

\section{Backaround for the study}

Hypertension is a common disease in the western society, and the treatment of patients with this disease constitutes a major part of a prysician's daily workload. It has been estimated that 24 million adult Amerlcans have mild hypertension,

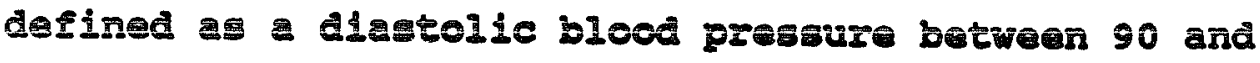
$104 \mathrm{mmig}$. The incidence of mild hypertension increases with age and is common in both men and women. In certain age groups, as many as $30 \%$ are effected by this disease. Because of its magnitude, hypertension i. major health problem in the United States (wenger, Mattson, Furberg, Elinson, 1984C). 
Over the past 10 years, there has been a steady increase in the number of asymptomatic people with mild hypertension who have been treated with hypertensive drugs. People in the United states are affected more than any other country. The expanding treatment of these 20-25 million people unguestionably represents the most extensive use of drugs ever attempted for the prevention of a disease (Hyman a Raplan, 1985). In treating patients with hypertension, physicians who ars successiul in controling blood pressure may be unaware of the negative effect that anti-hypertensive drugs can have on the quality of life (i.e., physical, emotional, sexual, and social functioning) of their patients. Given the increasing array of anti-hypertensive drugs currently available, physicians are faced with many choices in selecting medications that are effective with Iimited side elfects. The potential adverse affects of arugs on the quality of 11 te of patients with cardiovascular disease are becoming more widely respected by health professionals (Croog, Levin, Testa, Brown, Bulpitt, Jenkins, \&lerman, 1986). 


\section{Significance of the problem}

Many studies have shown that hypertensive patients undergning long-term arug therapy suffer adverse side effects affecting their quality of life (Bulpitt, Dollery, \& Carve, 1974; Bulpitt, Hoffbrand, \& Dollery, 1976; Bulpitt, 1982; Croog et al., 1986; Fletcher, \& Bulpitt, 1985; Jachuck, Brierly, \& Jachuck, 1982: Fidson, 1971). Idea11y, a long-term, comprehensive evaluation of the effect of antihypertensive treatment on the quality of life should be used in a clinical therapeutic assessment (Wenger, Mattson, Furberg, Elison, 1984a). However, most of the guestionnaires available are not suitable since their indices depend only on performance and ignore symptoms and feelings. Other restrictions include primarily time constraints, a feasible study design, and the need for a highly trained staff to administer the tests (Wenger, Mattson, Furberg, \& Elison, 1984b). A more reasonable approach is to develop a quality of life questionnaire assessment instrument speciflcally for use in a clinical setting. BY designing a new assessment instrument for a specific purpose, the investigator gains precision of measurement at the cost of generalizing the results. 
In creating a new assessment instrument, it is important to determine the reliability and validity of the assessment instrument (wenger et al., 1984a).

\section{Statement of the Purpose}

The purpose of this study was to estimate the reliability and content validity of a new cuality of life guestionnaire developed by the Institute for Aerobic Research (Dallas, TX). This questionnaire was to be used in clinical trials with hypertensive patients undergoing long-term arug therapy.

\section{Approach to the Problem}

Thirty-nine hypertensive male patients undergoing long-term arug therapy were used as subjects. The subjects ranged in age from 31-57 years. First, 20 experts in the field of hypertension evaluated the questionnaire for its content valiaity. A factor analysis was used to further test the content validity of the questionnaire. Secondly, the quality of Iife questionnaire was given once to each patient in order to estimate its reliability. It was simple to administer, and it took into account the three 
main components of the quality of life spectrum (functional capacity, perceptions, and symptoms). A coefficient alpha estimate was used to determine the internal consistency of all questions from each identified factor.

\section{Delimitations}

This study was delimited to 39 hypertensive patients who were involved in a 2-year study on the anti-hypertensive effects of fosinopril sodium, propranolol hydrocloride, and a program of aerobic exercise. The study was completed in June, 1989.

\section{Iimitations}

The factors in this study which could not be controlied included:

1. Honesty of the subjects when answering the questionnaire.

2. Inability to control the changes that might have occurred in the quality of life of each patient which might have been due to factors other than the effect of drug therapy. 
3. Unavailability of a larger sample of subjects to estimate content validity.

\section{Definition of Terms}

Asymptomatic: A body condition that does not indicate 11lness (Hornby, 1975).

Clinical Trials: A controlled setting for testing under medical supervision.

Experts: Medical doctors and/or exercise physiologists who had been involved in previous studies with hypertensive patients undergoing longterm drug therapy or who were involved in the present long-term drug therapy study. All experts had administered quality of life guestionnaires for at least two years or longer.

Hypertension: A disease defined as diastolic blood pressure of $90 \mathrm{~mm}$ mg or higher, or a systolic blood pressure greater than 140 mmig (The 1984 Report of the Jolnt National Committee on Detection, Evaluation, and Treatment of High Blood Pressure, 1984).

Quality of life - defined under three broad components:

a) Functional capacity - daily routine, 
social, intellectual, emotional, and economical.

b) Perception - health status and well-being (life satisfaction).

c) Symptom - disease under study and other illness (Wenger, et.al., 1984a).

ouality of Iife ouestionnaire: A questionnaire developed by the Institute for Aerobic Research (Dallas, TX) in order to test the quality of life of hypertensive patients undergoing long-term drug therapy.

\section{Summary}

This chapter Included the introduction, background for the study, signiflearee of the problem, statement of the purpose, approach to the problem, delimitations, limitations, definitions of terms. 
CHAPTER II

\section{Review of Iiterature}

\section{Introduction}

"Mild hypertension is the prototype disease for the class of conditions in which the patient is ambulatory, usually asymptomatic, and sess vell" (Wenger et al., 1984c). The diagnosis of hypertension in adults 18 confirmed when the average of two or more diastolic blood pressure checks on at least two subsequent visits 1890 ming or higher, or when the average of multiple yyetolic blood pressure on two or more mubeguent visits is consistently greater than $140 \mathrm{mming}$ (The 1984 report of the Joint National Committe on Detection, Evaluation and Treatment of Iigh Blecd Pressure, 1984): The incidence of ild hypertension Increases with age and 18 common in bots men and momen (The 1984 report of tho Jolnt Mational Comitter on Detection, Evaluation and Treatment of High Blood Pressure, 1984). More than 60 million people in the United stater have elevated blood pressure (140/90 mifig or greater) or have been informed by a physician that they have 
hypertension. This chapter included a discussion of quality of life and hypertension, measurement of the quality of life, effect of long-term drug therapy on the quality of life, and labeling.

\section{Quality of Life and fypertension}

An important aspect of anti-hypertensive drug therapy that 1: often neglected by physicians, is its effect on the quality of 1ife of their patients. Some patients perceive the use of anti-hypertension medication to be more troublesome than their symptomless disease (Croog et al., 1986). This results in noncompliance and ineffective long-term treatment.

Quality of life has been defined under three broad components: functions, perceptions, and symptoms (wenger ot al., 1984a). Functions include activities Involved in dally personal functioning such as dressing, aating, meeting basic individual needs, and maintaining adequate physical activity. Involvement of social activities with friends, community interactions, sanily relationships, and marital satisfaction are other components of functional capacity. 
Intellectual functions include memory and alertness, the ability to comunicate, confidence in making decisions, and judgment. Manifestations of emotional status are mood changes, feelings of anger, guilt, hostility, depression, helplessness, sick-role behavior, satisfaction, expectations, fears, and concern about the future. A further dimension of the quality of life is the ability to maintain a satisfactory standard of living, datermined by income, insurance coverage, job satistaction, retirement benefits, and so sorth. This dimension is significantly influenced by the overall functional capac1ty.

Perceptions are defined as an individual's view of his or her situation. Inis ancompasses personal value fudgments of the components. Of particular interest are perceptions of general bealth status, level of well-belng, and atisaction with ifie. Symptoms of the alsease, por se, those induced by treatment or abolished by intervention, constitute the third major component of the cuality of 11 fe. Symptoms mill Influence the other two factors, functional capacity and perceptions. Is lact, 211 three are interrelated. 
Measurement of the Quality of Life

Quality of life data provides an independent evaluation of the success, or failure of an intervention, and may be the deciding factor in the final selection of therapeutic alternatives when survival advantages between treatments do not differ or are marginal. In a clinical trial involving chronic therapy, no matter how successful tho intervention, the effectiveness depends on long-term adherence to the therapy. qualty of 11fe variabies may help document attitudes, traits, and lifestyle changes that can influence compliance with a particular intervention (Henger et al., 1984a). Ideally, long-term, comprehensive evaluation of the effect of anti-hypertensive treatment on the quality of Iife should include all three components discussed above however, there are arious refrictions on utiliaing this approach in a clinical setting. These include primarily time constraints, a leasible study design, and the need for a highly trained staff to adminieter the teats (wenger at al. 1984a). Most of the questonnaire available are not sultable for use in a clinical therapeutic asmessment (wenger et al.. 1984b). Many indices depend only on performance and 
ignore symptoms or feelings. Also the validity, reliability, and sensitivity of these indices are variable, and may only identify gross dysfunction. Two well-known indices, the sickness Impact Profile (SIP) and the Index of Rell-Being, take into account performance, social activity, mobility, and emotional state and have been shown to have high reliability and validity (Bergner, Bobbitt, Cartar, 1981; Krauth, 1982). For instance, the SIP was developed to provide a measure of perceived health status that was sensitive enough to detect changes or differences in health status that would occur over time or between groups. It was designed to be broadly applicable across types and severities of 11lness and across demographie and cultural subgroups. The SIP was intended to provida a measure of the effects or outcomes of health care that could be used for evaluation, program planning and policy formulation. A large field trial on a randon sample of prepaid group practice patients and smaller trials on samples of patients wik hyperthyroiaism, rheumatoid arthritis, and hip replacement were undertaken to assess reliabllity and validity of the SIP and also to provide data for category and item analysis. The results showed a high test/retest reliabllity 
$(\underline{R}=.92)$ as well as internal consistency

$(\underline{R}=.94)$. The SIP contains 136 items in 12

categories. The major limitations of the SIP were its length and the lack of disease specific indices sensitive to treatment effects.

In addition, the Index of Well-Being (IWB) was based on objectively reportable facts that occurred on a given day over a 6-day perlod preceding the interview. It covers institutionalization, selfcare, social activities and reports of symptoms and problems. Also, it incorporate social preferences for Lunctional states (Wenger at al., 1984b). Further, the error characteristics of the functional state classification, as determined on the basis of data obtained Irom 1,324 subjects with 211 prevalence diseases and injuries were as follows: sensitivity, $\underline{R}=.90 ;$ specificity, $R=.99 ;$ predictive value dysfunctional, $\bar{B}=.95$; and predictive value functional, $\mathrm{R}=.98$ (Raplan, Bush, Berry, 1976). Also, the test-retest rellability for flnal codes on successive days was high $(R=.98)$. This included actual state changes between two days as well as any misclassification. The major limitations of the IWB were its complexity and the need of trained interviewers to administer it. It described the 
patient's state at one point in time; additional data would be needed for estimating future quality of Iife. Iike other instruments, the IWB questionnaire does not identify the cause of a change in a score (Wenger et al., 1984b). Since both of these indices assess fairly broad functional states, their ability to discriminate between more subtle changes produced by the disease state of treatment has been cuestioned (Fenger at al., 1984b). Thus, the use of an instrument designed to measure changes produced by $a$ specific disease or trastime becomea essential. In summary, the SIP and IWB guestionnaires lack disease-specific indica thet are sensitiv to a particular 111ness or treatrent effects.

\section{Ffect of Iong-tern Drug therapy on the ouality of Iti}

Iong-tern drug therapy can produce a wide range of side effects. These side effect may interfere with the enfoymant of lood, sedentary hobbies, exercise, and sex. For Instance, Bulpitt and Dollery (1973) inventigated the ide-erfects of hypoterisive agents evaluated by a sel-administered guestionnaire which was completed by 477 patients in a hypertension 
clinic. The complaints of the parients were analyzed according to the type of therapy being given and the dose of drug taken. Methyldopa therapy was associated with sleepiness, weakness of the limb, sleeping longer at night, and rising more frequently at night to pass urine. Bethaniaine administration was related to postural hypotension, impotence, and failure of ejaculation, and more frequent opening of bowels. The authors concluded that more research was required into symptoms and side-effects experienced by hypertensive patients. Fupthermore, similar results were again found by Bulpitt et al. (1974) in a study investigating the guality of life of normotensive control subjects and patients taking anti-hypertensive agents. The study was conducted in three phases: a period of checking that patients understood the questionnaire, a survey of patients in the Hammersmith Hospital Hypertension Clinic, and a survey of normal subjects registered with general practitioners at a local health center. At phase I (a period of three months), every fifth patient attending the hypertension clinic was asked to complete the questionnaire while waiting in the clinic. At the ensuing routine interview, the . questionnaire was examined and it was confirmed that 
the patients had understood the questions by reviewing the answers given. At phase II (a period of two months), the patients who had not previously completed a questionnaire were selected to answer the questionnaire. At phase III, 231 patients were randomly selected from the age/sex register of a health center to answer the questionnaire (normotensive controls). The results showed that the treated hypertensive patients complained more of sleepiness, postural hypotension, dry mouth, nocturia, diarrhea, slow walking pace, impotence and failure of ejaculation, than did the normotensive controls. Headaches and depression were more common in women than men in all age groups. These two symptoms (headaches and depression) were reduced in the elderly. Black patients slept less than caucasian patients and complained more of weakness in the limbs. It was concluded that the questionnaire could be of great value in the before and after treatment situations and could be used to compare different treatment regimes. Thus, both of these studies used the same questionnaire (High Blood Pressure Health Survey) to measure the quality of life and side-effects of hypertensive patients undergoing drug-therapy. However, this questionnaire 
addressed mainly the symotom domain of the guality of life spectrum. Ideally, the instrument of use should measure all three domains: Iunction, perception, and symptom.

In addition, Bulpitt (1982) further investigated the effects of several other anti-hypertensive drugs on the quality of iffe. It was found that propranolol and bethanidine increased uneteadiness and weak Iimbs, and guanethidine produced unsteadiness, diarrhea, and failure of ejaculation. Depression and other psychiatric morbidity were also reported as a result of anti-hypertensive arug therapy in this study. In another survey conducted by Jachuck and colleague (1982), the quality of life of 75 gatients with controlied hypartersion was assessed. The group consifted of 41 women and 34 men. The patients were given a self-administered

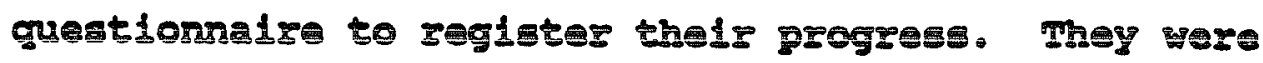
also asked to answer by direct questloning if they had felt improved, worse, or had found no appreciable difference in their inical and general condition after therapy. A relative or close companion of each patient was also given a self-administered questionnaire (Quality of Life Impairment Scale-QIIs) and was requested to respond without coneulting the 
patient. The overall assessment of the general practitioner was also recorded. The responses from the doctors, patients, and the close companions were assessed separately by an observer who had no knowledge of the patients nor their sex or therapeutic regime. The QIIs asked the relative or close friend to evaluate advarse changes in the patient in 20 areas and yielded a score of 0 to 32 . The scal included a ser 1nterest item which was not scored since the respondent may not have been able to evaluate the patient's sexuality. The scores rrom the scale were divided into three groups representing mild, moderate, and severe changes in quality of 111. The oIIS, a lts nam implied, only assessed the degree of impalment of 118e. Also, it manly addressed questions related to the function domain of the quality of 1ife apectrum. The results of the overall assemsment of the doctor: the patient: and that of their close companions differed considerably. The doctors registered 100 improvemest as (a) they had adeguately controlled the bieod pressure, (b) there had been no clinical deterioration since the treatment, and (c) the patiente had not complained about the effect of treatment to the doctors. Further, 48 of the patients said they felt better as 
a result of starting the treatment. In contrast, to the assessments of both physicians and the selfreporting of the patients, the relative's questionnaize rated 19 patients (258) to have suffered mild adverse changes and 33 patients (30\%) to have severe impaiment after receiving antihypertensive therapy. The deteriorations were attributed to undue preoccupation with sickness, decline in asergy, general activity, and sexual activity. The authors suggested the use of such an assessment in social readjustment and occupational rehabilitation.

Croog at al. (1986) investigated the effects of captopril, mothyldopa, and propranolol on the gual1ty of 115 of 626 men with mild to moderate hypertension. All patients were caucasian males between the ages of 21 and 65 years, full-time aployed, and had a pimary diagrosis of estatial hypertension (a median diastolic blood pressure in the seated position of 92 to 109 wing on three daterainations within Iive minutes). Upon entry into the study, each patlent was randomly assigned to receive one of three druge (captopril, methyldopa, or propranolol) in two different periods. Perlod A being the placebo period and period B being the 
active medication period. Placebo tablets with the same physical characteristics as ach of the tast drugs were prepared. During period A, the patient took three placebo tablets twico a day for four weaks. During period $B$, the patients received the assigned active drug plus two placebo tablets twice a day to maintain the double blinding. The patlents were medically evaluated at 2-week intervals during period $A$ and on a monthly bas during period $B$. For the quality of 119 otudy, Interviewe were carried out in a four-stago program: otage I, at the beginning of pariod A: stage II, at the and of the four weeks in perlod A: stage III, after elght weoks of period 8 ; and stage IV, after 24 weeke of period B. The quality of 11fe asmeresent was based on Ifve measures: (a) the sense of we1l-belng and satisfaction with 11fe, (b) the physical state, (c) the emotlonal state, (d) Intellective Eunctioning, and $(\theta)$ the ablity to persora in social roles and the degre of atisection derived from those 50108. The sesults 13d1eated that the three treatement groups did not diffor in terms or measures of socialization, vimual ranory, and sose otber aspects of cognitive functioning and omotional distress. However, clear dilerences in other 
indices of quality of life were evident. At $24^{21}$ weeks, the captopril group was better off than the methyldopa in terms of the measures of well-being, anxiety, depression, physical symptons, sexual dysfunction, cognitive function, work performance, and satisfaction with 11fe. Patients taking propanolol also reported better work performance than patients taking methyldopa. The authors concluded that ant-hyportonsive agents have disferent ofrects on the quality of 11te and can be maningrully assassed with avallable prychosocial measures. However, the use of 10 different Instrumanta to measure the quality of Iffe may not be feasible to moet clinical trials although all thres domain of the guality of 1 ife mpectrum in this study were addresed. The main restrictione included the need of a highly trained atar to adninister the tects and time constrainte.

In surnary, the studies discussed above have show that different ant 1 -hypertensive druge Influense verlous apects of the guality of 11 fe of patient. Also, the guestiomalres used to acces the quality of 11fe of patients did not alway evaluate the three domains of the quality of I1fe spectrum: Iunction, perception, and symptos. 
Ideally the instrument of use should include all three domains.

\section{Iabeling (Treatment situation)}

Increased absenterism from work has been found in hypertensive patients who were aware of their disease status (Fletcher et al., 1985: Haynes, sackett, Taylor, Gibson, Johneon, 1978). Diagnosed hypertensive patients have been described to gemerally not seel as well ar normoteneive control subjects, and this leature appears unchanged by treatment. Hayne et al. (1978) investigated labeled hypertensive employee absentedsm at canadian steel mill. Data were gathered before and after screening steel workers Ior hypertension. In brief, two-thirda $(5,400)$ of the ande amployees were asked whether they had over bees told thet bhey had high blocd prosture, after wich they ware screened for hypartension. A total of 245 mies at the solsowing salteria: average flfth-phase diatcolle blood preasure (higher than 95 miff). no ant -hypertens 1ve therapy for at least 1 ix months before the screening, no other de1ly medications, and no ranedial econdary lorm of hypertension. IInety-four percont of these male 
consented to participate in a six-month randomized trial of compliance improving strategies. Absenteeism was determined directly from routine company time-clock records. The results showed that labeling of patients as hypertensive increased the mean absenteeism 5.2 days per year (SD \pm 2.3 days). This eighty percent increase exceeded the rise in absenteeism in the general employee population during this period. The main Factors associated with increased absenteeism were becoming atare of the condition and low compliance with treatment. subseguent absenteeism among patients unaware of their hypertension before screening was not related to the degree of hypertension, whether the worker was started on therapy, the degree of blood pressure control achieved, or exposure to attempts to promote compliance. It was concluded that these results have major implications for hypertension screening programs, especially since absenteeism rose among those previously unaware of their condition, regardless of whether anti-hypertensive therapy was begun.

In addition, several other studies have shown the effect of labeling on various measures of psychological functions and well-being. The Dofasco 
study (Mossey, 1981) provided an opportunity to study prospective changes in psychosocial behavior as a result of labeling. Baseline data were collected on 230 steel workers with hypertension before their blood pressure status was revealed to them. The data included measures of marital adjustment and selfperceptions of well-being, aliveness, powerfulness, and goodness. Follow-up measurements of these attributes were gathered six and twelve months after screening. When the men with hypertension were compared with age-matched untreated normotensive controls, a deterioration in marital satisfaction was observed. This observed decrease in marital satisfaction occurred independent of prior knowledge of hypertension status, treatment status, or compliance and was related to an increase in absenteeism.

Two cross-sectional studies offer additional evidence that there is an impact from patient labeling when hypertension is diagnosed (Monk, 1981; Soghikian, Fallick, Hunter, VYY, 1981 ). In a mult1-phased health check-up program, 52,948 people underwent diastolic pressure checks, completed a self-administered questionnaire on whether they had been labeled, and answered questlons that measured 
their psychological status (Soghikian et al., 1981). since only one blood pressure measurement was taken and in view of the variability associated with the one time reading, hypertension was defined as a diastolic pressure in excess of $105 \mathrm{mmig}$. From the first two measures, four groups were formed:

(a) labeled hypertensives, (b) unaware hypertensives, (c) mislabeled normotensives, and (d) normotensives. Analysis were then carried out to summarize the psychological distress of each group, adjusted for age, gender, race, and treatment status. Labeled individuale (group $I$ and 3 ) oxhibited uniformly greater psychological distress than the other two groups. There was no difference in psychological distress between unaware hypertensives and normotensives. A striking finding of this study was the high level of psychological distress among people witi normal blood pressure who had been mislabeled and were convinced they had hypertension. Finally, when blood pressure was taken into account, greater psychological alstress was observed among the untreated Individuals than among those who were successiully controlled.

A second cross-sectional study was completed in early 1970 as part of the lirst health and nutrition 
survey conducted in the United states (Honk, 1981). A representative sample of 3,854 individuals were interviewed, examined, and administered a questionnaire about their psychological well-being. Blood pressure status was not known at the time the general well-being questionnaire was administered. Blood pressure ratings in excess of $160 / 95$ mming met the definition of hypertension, and people with bypertension were divided into three groups: (a) unaware, (b) labeled but untreated, and (c) labeled and treated. After adjustment for age, gender, and racial differonces, a clear hierarchy of psychological well-being was found among unaware hypertensive patients and normotensives, who were identical. Labeled and ireaced hypertensive patients were at the other end of the hierarchy, with the lowest psychological well-being, and labeled but untreatad hypertansive patiente in the midale. Finally, labeled and treated hypertensive patients reported a significantly higher rate of emotional problems and nervous breakdowns than the unaware group.

In summary, diagnosed hypertensives have been described to generally feel 1 ess well than normotensive control subjects. Also, diagnosed 
hypertensives have shown a decrease in marital

satisfaction, greater psychological distress, and lower ratings of psychological well-being.

\section{Summary}

This chapter included a discussion of quality of Iffe and hypertension, measurement of the quality of life, effect of long-term drug therapy on the guality of life, and labeling. 
CHAPTER III

\section{Methods}

\section{Introduction}

In this chapter information on the subjects, the instrument, and measurements and methods is presented. The measurement; and metnods lnclude content validity, reliability measurement, collection of data, and physiological parameters.

\section{Subjects}

Thirty-nine hypertensive male patients who underwent long-term drug therapy were used as subjects. Th subject: ranged in age erom 31-57 years. Ail subject had mila to moderate essential hypertension (1.0., diactollc blood preseure ranging Irom 95 to $109 \mathrm{mmg}$ ) measured on two occaslons that were separated by two weeks. All subjects were involved in a 2-year study of anti-hypertensive effects of losinopril sodiun, propranolol hydrocloride, and a program of aerobic exercise. The study was concluded in June, 1989. All procedures 
were fully explained to the subjects and consent was obtained from each subject prior to any data collection (Āppendix A).

\section{Instrument (Appendix B)}

A quality of life questionnaire developed by the Institute for Aeroblcs Research (Dallas, TX) for hypertensive patients was examined for its reliability and content validity. The original questionnaire contained only 10 questions (quastions 1 through 10). For the purpose of this study, 11 more questions were added (questions 11 through 21). The new questione were developed according to the quality of life spectrum definition. For ingtance, questions $3,5,9,10,11,12,13$, and 16 were intended to represent the function domain. Questions $1,4,6,7,8,14,15$, and 17 ware intended to represent the perception domain. questions 2,18 , 19, 20, and 21 re intended to represent the symptom domain. 


\section{Content Validity}

Twenty experts evaluated the questionnaire for claricy and content validity. Experts were given a complete definition for the three domains (function, perception, and symptom) of the guality of life spectrum. Each expert, then, aubjectively classified each question in the domain to which he/she believed each question belonged.

A principal component lactor analysis with an orthoganal rotation was used. Eingenvalues greater than 1.0 were used as the criterion for identification of the signiflcant contructs (factors) reprezented by the 21 guestion in the cueationnaire. Factors wero given descriptive titles based on the guestions determined to be wost highly related to a factor loading. mis classificator was ther compared and analyzed with the subjective evaluation of the experts as well as tho original classisication as ldentirled in the previous mection. 
In order to determine the internal consistency (reliability) of the questionnaire, a coefficient alpha was calculated for the questions within each of the significant constructs (factors) identified by the factor analysis. An alpha coefficent greater than . 70 was considered to be indicative of acceptable reliability.

\section{Ruyetijogical Parameterg}

The physiogical parameter of each patient were measured by the physician involved in the long-term drug theragy study. Physological parameters finesured included supine aystolic and diastolic blood pressure, resting heart rate, age, height, and weight.

\section{Coldection of Data}

The hypertensive patient's quality of 11 fe guestionnaire was given once to all patient's. The questionnaire was handed to each patient during his blood pressure check visit at the Cooper clinic in 
May, 1989. They were asked not to write their names on the questionnaire. A code number (1-39) was assigned to each patient upon receiving the questionnaire. The number was witten by the researcher, Carlo sottovia, in the upper right hand corner of the questionnaire's cover page. Further, each code number was matched to each patient's 1nitiald. All patients recelved a copy of their assigned code number and they could withdraw their participation in the otudy at any time. Finally, all questionnaires and code numbers were kept in a confidential 11lo by the zeseareher during the trudy añ after the completion of the study. All patients were scheduled for thelr blood preseure check during the weoks of (May 15th thru May 19 th and gay 22 th thru May 25th). Approximately 10 patients were checked a day. Patiente were sheduled at one hour intervals and were asked to complete the questionnalre belor thoir blood grosere measurament.

\section{Sumary}

This chapter included information on abject for the study, the instrument, and measuraments and 
methods. The measurements and methods included

content validity, estimation of reliability, collection of data, and physiological parameters. 
GHAPTER IV

Results, Discusson and conclusions

\section{Introduction}

This chapter includes analysis of data, summary of findings, discussion of findings, conclusions, weaknesses of study, and recommandations for future research. The analysis of data includes the physiological parametere of abjects, descriptive statistics of questions, descriptive responses of subjects, and estimation of content validity and reliability measurements.

\section{Analysia of Data}

\section{Phusiologica 1 Paramectere of subtect: Table 1 and} Table 2.

Thirty-nine hypertensive patients were used as 8ubjects. Their age ranged from 31 to 57 years (M \pm SD $=44.7 \pm 5.5$ years). Diastolic blood pressure ranged Irom 64 to 108 matig (RA \pm SD $=85.6 \pm$ $7.6 \mathrm{~mm} f \mathrm{~g}$ ) and systolic blood pressure ranged from 112 to $184 \mathrm{mming}(K \pm S D=135.2 \pm 16.8 \mathrm{mming})$. 
Table 1

physiological parametars of subjects

\begin{tabular}{|c|c|c|c|c|c|c|c|}
\hline Sub. & Sup.B.P. & R.H.R. & Age & $\mathrm{HC}$ & & & Wt \\
\hline 1 & $122 / 86$ & $47 \mathrm{bpm}$ & 48 yrs & 180 & cm & 78 & $\mathrm{~kg}$ \\
\hline 2 & $112 / 64$ & $54 \mathrm{bpm}$ & $36 y 58$ & 175 & cm & 111 & $\mathrm{~kg}$ \\
\hline 3 & $124 / 82$ & $60 \mathrm{bpm}$ & 39 yr & 179 & cm & 94 & $\mathrm{~kg}$ \\
\hline 4 & $168 / 94$ & 58 b령 & 47 y 18 & 158 & $\mathrm{C}_{\mathrm{B}}$ & 69 & $\mathrm{~kg}$ \\
\hline 5 & $140 / 92$ & $48 \mathrm{bpm}$ & 47 yrs & 182 & $\mathrm{~cm}$ & 106 & $\mathrm{~kg}$ \\
\hline 6 & $112 / 82$ & $68 \mathrm{bpg}$ & 44 Y78 & 195 & $\mathrm{Cx}$ & 80 & $\mathrm{~kg}$ \\
\hline 7 & $184 / 108$ & $63 \mathrm{bpm}$ & 48 yrs & 169 & $\mathrm{Cm}$ & 96 & $\mathbf{k g}$ \\
\hline 8 & $114 / 82$ & 54 bpm & $45 y r s$ & 169 & can & 100 & $\mathrm{~kg}$ \\
\hline 9 & $132 / 96$ & $75 \mathrm{bpm}$ & $31 \mathrm{yx}$ & 191 & $\mathrm{~cm}$ & 93 & $\mathrm{~kg}$ \\
\hline 10 & $132 / 82$ & $74 \mathrm{bpm}$ & 43 yT & 187 & ctm & 100 & $\mathrm{~kg}$ \\
\hline 11 & $116 / 78$ & $54 \mathrm{bpa}$ & $43 y$ & 173 & Cim & 95 & $\mathrm{~kg}$ \\
\hline 12 & $138 / 88$ & $60 \mathrm{bpm}$ & 37 yx & 182 & Cxis & 93 & $\mathrm{~kg}$ \\
\hline 13 & $169 / 92$ & $50 \mathrm{bpm}$ & 47 y'a & 181 & Cm & 70 & $\mathrm{~kg}$ \\
\hline 14 & $128 / 76$ & 54 bpm & $42 y 53$ & 191 & cm & 120 & $\mathrm{~kg}$ \\
\hline 15 & $130 / 86$ & 47 bpm & 53 yr & 184 & CS & 102 & $\mathrm{~kg}$ \\
\hline 16 & $128 / 88$ & 65 bpr & $51 \mathrm{y}$ & 166 & cas & 97 & $\mathrm{~kg}$ \\
\hline 17 & $140 / 74$ & $47 \mathrm{bpm}$ & $48 y r$ & 176 & Can & 77 & kg \\
\hline 18 & $138 / 82$ & $50 \mathrm{bpm}$ & $48 y$ & 182 & cm & 88 & $\mathbf{k g}$ \\
\hline
\end{tabular}


Table 1 (Continued)

Physiologtcal Parameter of sublects

\begin{tabular}{|c|c|c|c|c|c|c|c|c|}
\hline sub. & Sup.B.P. & R.R & A.R. & Ag & & Fint & & $w t$ \\
\hline 19 & $138 / 86$ & 57 & bpm & 52 & yrs & 170 & $\operatorname{con}$ & $72 \mathrm{~kg}$ \\
\hline 20 & $132 / 86$ & 60 & bpm & 33 & yrs & 170 & cin & $68 \mathrm{~kg}$ \\
\hline 21 & $126 / 80$ & 44 & bpm & 44 & yrs & 172 & $\mathrm{~cm}$ & $77 \mathrm{~kg}$ \\
\hline 22 & $128 / 84$ & 52 & bom & 46 & y58 & 172 & Ca & $72 \mathrm{~kg}$ \\
\hline 23 & $124 / 76$ & 57 & bpm & 44 & yrs & 189 & $\cos$ & $118 \mathrm{~kg}$ \\
\hline 24 & $144 / 82$ & 57 & bga & 44 & yxs & 173 & C용 & $65 \mathrm{~kg}$ \\
\hline 25 & $130 / 86$ & 54 & bpar & 36 & yrs & 175 & $\mathrm{~cm}$ & $102 \mathrm{~kg}$ \\
\hline 26 & $148 / 90$ & 75 & bpq & 57 & yre & 180 & cen & $75 \mathrm{~kg}$ \\
\hline 27 & $128 / 96$ & 58 & bpe & 43 & yres & 175 & Col & $83 \mathrm{~kg}$ \\
\hline 28 & $136 / 88$ & 68 & bpp & 45 & $y \geq$ & 172 & का & $101 \mathrm{~kg}$ \\
\hline 29 & $120 / 92$ & 68 & bpa & 46 & $y \mathbf{x}$ & 181 & cras & $125 \mathrm{~kg}$ \\
\hline 30 & $122 / 86$ & 75 & bpen & 53 & 감중 & 176 & $\mathrm{Cl}$ & $97 \mathrm{~kg}$ \\
\hline 31 & 172,190 & 89 & 39 & 39 & $y$ & 190 & - & sิ $\mathrm{kg}$ \\
\hline 33 & $132 / 76$ & 67 & bgm & 47 & y's & 175 & Gm & $90 \mathrm{~kg}$ \\
\hline 34 & $124 / 88$ & 48 & bpe & 52 & yrs & 176 & Gi & $90 \mathrm{~kg}$ \\
\hline 35 & $220 / 88$ & 48 & bpen & 45 & Y's & 177 & ca & $83 \mathrm{~kg}$ \\
\hline 36 & $162 / 98$ & 73 & bpa & 47 & $y \mathbf{3 8}$ & 177 & ca & $85 \mathrm{~kg}$ \\
\hline 7 & $132 / 86$ & 59 & bpen & 41 & y's & 276 & ca. & $90 \mathrm{~kg}$ \\
\hline 38 & $156 / 80$ & 60 & bpes & 42 & $y=$ & 177 & cid & $85 \mathrm{~kg}$ \\
\hline 2 & $144 / 80$ & 58 & 16 & sid & yxe & 180 & 9 & $80 \mathrm{~kg}$ \\
\hline
\end{tabular}


Table 2

Descriptive statisticg of the physiolocical

Parameters of subjects

\begin{tabular}{|c|c|c|}
\hline & Mean & standard Deviation \\
\hline $\begin{array}{l}\text { Systolic Blood } \\
\text { Pressure: }\end{array}$ & $135.2 \mathrm{mmHg}$ & $16.8 \mathrm{mmkg}$ \\
\hline $\begin{array}{l}\text { Diastolic Blood } \\
\text { Pressure: }\end{array}$ & $85.6 \mathrm{mmig}$ & $7.6 \mathrm{mmHg}$ \\
\hline $\begin{array}{l}\text { Resting Heart } \\
\text { Rate: }\end{array}$ & 59.7 bpas & $9.8 \mathrm{bpm}$ \\
\hline Age: & $44.7 y x$ & $5.5 Y r z$ \\
\hline Height: & $177.5 \mathrm{~cm}$ & $7.5 \mathrm{~cm}$ \\
\hline weight: & $89.5 \mathrm{~kg}$ & $13.9 \mathrm{~kg}$ \\
\hline
\end{tabular}


Also, the subjects' height and weight ranged from $158 \mathrm{~cm}$ to $191 \mathrm{~cm}(\mathrm{M} \pm \mathrm{SD}=177.5 \pm 7.5 \mathrm{~cm})$ and $65 \mathrm{~kg}$ to $125 \mathrm{~kg}(M \pm S D=89.5 \pm 13.9 \mathrm{~kg})$, respectively. Finally, resting heart rate ranged from $47 \mathrm{bpm}$ to $89 \mathrm{bpm}(\mathrm{M} \pm \mathrm{SD}=59.7 \pm 9.8 \mathrm{bpm}$ ). Descriptive statistics of questions: Table 3.

This table presents the means and standard deviations of the response of the patients to the questions. The man and atandazd deviations for the questions ranged from 1.36 to 2.56 and .62 to 1.21 , respectively.

Descriptive responses of subjects: Table 4. This table describes the frequency of responses of all questions. The percentage of responses of all questions occurred most Irequently on question choices 1 through 3 (positive responses), with question choice 2 having the highest percentage of responses.

Content Validity: Table 5.

Twenty experts evaluated the quality of 11 fe questionnaire for ito content validity. Each expert classified each question according to the guality of ife domain in which he/she believed each question belonged. A complete definition of the three domains of the quality of life spectrum (function, 
Table 3

Descriptive statistics for the 21 questions

\begin{tabular}{|c|c|c|}
\hline ouestion & Mean & Standard Deviation \\
\hline 1 & 2.28 & 1.00 \\
\hline 2 & 2.56 & .99 \\
\hline 3 & 2.41 & 1.07 \\
\hline 4 & 1.90 & .88 \\
\hline 5 & 1.64 & .71 \\
\hline 6 & 2.36 & 1.20 \\
\hline 7 & 1.67 & .62 \\
\hline 8 & 2.00 & .86 \\
\hline 9 & 2.31 & .89 \\
\hline 10 & 1.95 & 1.21 \\
\hline 11 & 1.36 & .63 \\
\hline 12 & 2.00 & .79 \\
\hline 13 & 2.13 & .86 \\
\hline 14 & 2.56 & 1.10 \\
\hline 15 & 1.67 & .66 \\
\hline 16 & 1.97 & .71 \\
\hline 17 & 1.97 & .71 \\
\hline 18 & 1.85 & .71 \\
\hline 19 & 2.31 & .86 \\
\hline 20 & 1.44 & .60 \\
\hline 21 & 1.77 & .67 \\
\hline
\end{tabular}


Table 4

Descriptive Responses of subjects

\begin{tabular}{|c|c|c|c|c|c|c|}
\hline \multirow[t]{2}{*}{ Response } & \multicolumn{2}{|c|}{$\begin{array}{l}\text { Very } \\
\text { Positive }\end{array}$} & \multicolumn{2}{|c|}{ Response 6: } & \multicolumn{2}{|c|}{$\begin{array}{l}\text { Very } \\
\text { Negative }\end{array}$} \\
\hline & 1 & 2 & 3 & 4 & 5 & 6 \\
\hline \multicolumn{7}{|l|}{ Questions } \\
\hline 1 & $28.2 \%$ & $25.6 \%$ & $35.9 \%$ & $10.3 \%$ & & \\
\hline 2 & 7.78 & 51.38 & 23.18 & $12.8 \%$ & 5.18 & \\
\hline 3 & $15.4 \%$ & $48.7 \%$ & 23.18 & 5.18 & 7.78 & \\
\hline 4 & 35.98 & 43.68 & 17.98 & & 2.68 & \\
\hline 5 & 48.78 & 38.58 & 12.88 & & & \\
\hline 6 & $20.5 \%$ & 48.78 & 17.98 & & 12.88 & \\
\hline 7 & $41.0 \%$ & $51.3 \%$ & 7.78 & & & \\
\hline 8 & 30.88 & $43.6 \%$ & 20.58 & 5.18 & & \\
\hline 9 & $17.9 \%$ & 43.68 & 28.28 & $10.3 \%$ & & \\
\hline 10 & $41.0 \%$ & $43.6 \%$ & 5.18 & 2.68 & $5.1 \%$ & $2.6 \%$ \\
\hline 11 & 71.88 & $20.5 \%$ & 7.78 & & & \\
\hline 12 & 28.28 & 46.28 & 23.18 & $2.6 \%$ & & \\
\hline 13 & 23.18 & 48.78 & 20.58 & $7.7 \%$ & & \\
\hline 14 & 17.98 & 30.88 & 33.38 & $12.8 \%$ & 5.18 & \\
\hline 15 & 43.68 & 46.28 & 10.38 & & & \\
\hline
\end{tabular}


Tabie 4 (Continued)

Descriptive Responses of subjects

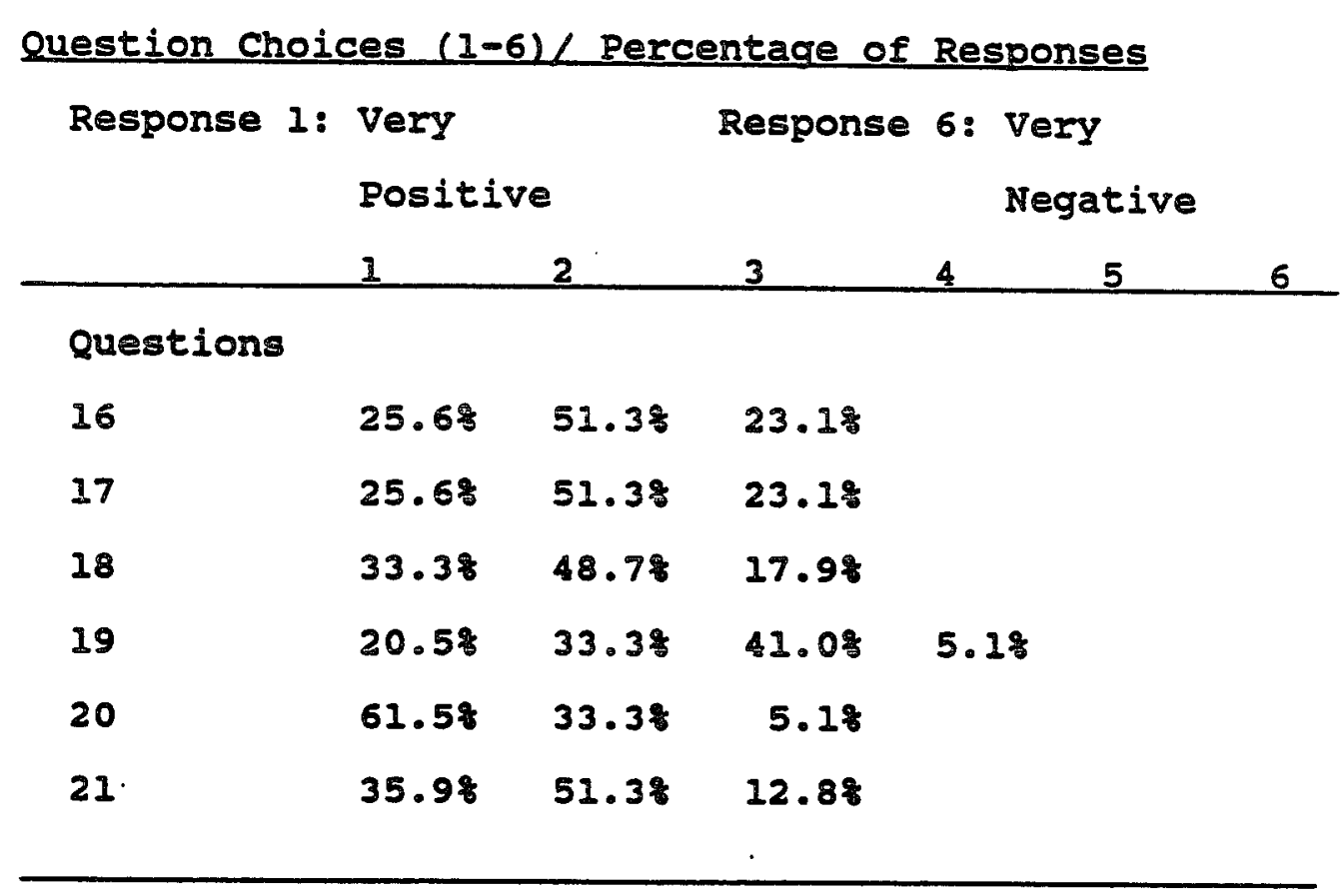


Table 5

Content Validity

Number of Observations per

Domain for Each Question

(20 observations maximum)

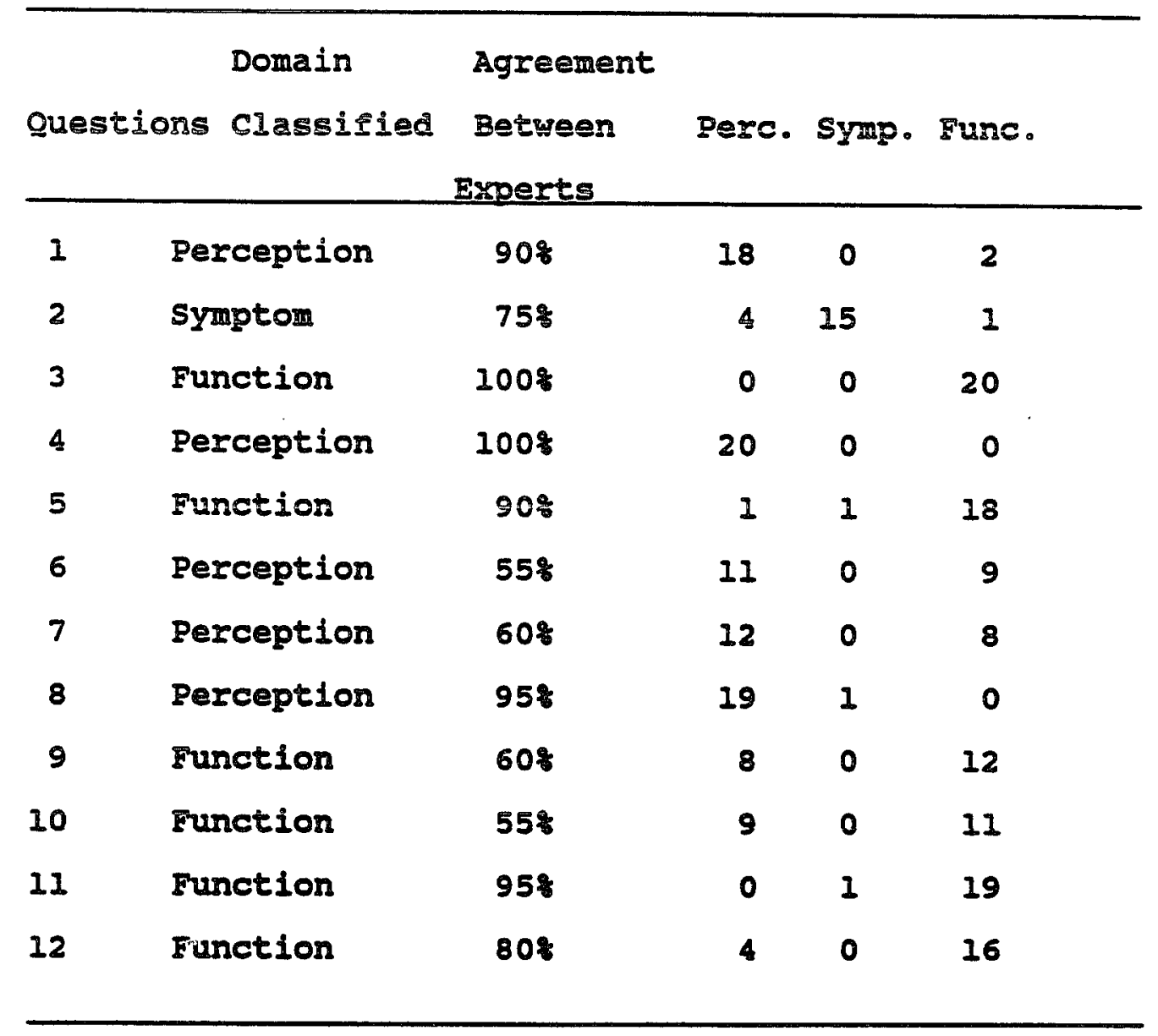


Table 5 (Continued)

Content Validity

Number of observations per

Domain for Each Question

(20 observations maximum)

\begin{tabular}{|c|c|c|c|c|c|}
\hline Questions & $\begin{array}{l}\text { Domain } \\
\text { Classified }\end{array}$ & $\begin{array}{l}\text { Agreement } \\
\text { Between } \\
\text { Exparts }\end{array}$ & Perc. & symp. & Fune. \\
\hline 13 & Function & 708 & 5 & 1 & 14 \\
\hline 14 & Perception & 608 & 12 & 1 & 7 \\
\hline 15 & Perception & $80 \%$ & 16 & 1 & 4 \\
\hline 16 & Function & $85 \%$ & 2 & 1 & 17 \\
\hline 17 & Perception & 808 & 16 & 1 & 4 \\
\hline 18 & symptom & 958 & 0 & 19 & 1 \\
\hline 19 & Symptom & 958 & 1 & 19 & 0 \\
\hline 20 & symptom & 958 & 0 & 19 & 1 \\
\hline 21 & symptom & 958 & 0 & 19 & 1 \\
\hline
\end{tabular}


perception, and symptom) was given beforehand to each expert. This subjective evaluation showed the following responses:

1) Twenty experts agreed with each other that questions $18,19,20$, and 21 (100\% agreement) were measuring the symptom domain. Also, fifteen experts classified question 2 in this domain (75\% agreement).

2) Twenty experts agreed with each other that question 4 was measuring the perception domain (100\% agreement). Further, 19 and 18 experts classified questions 8 and 1 in this domain, respectively $195 \%$ and $90 \%$ agreement). Moreover, 16 experts classified questions 15 and 17 in this domain ( $80 \%$ agreement) as well: In addition, 12 experts classified questions 7 and 14 in this domain (608 agreement). Finally, 11 experts agreed that question 6 was measuring the perception domain (55\% agreement).

3) Question 3 was classified in the function domain with $100 \%$ agreement among the experts. Also, questions 11, 5, 16, 12, and 13 showed a 95\%, $90 \%$, 85\%, 80\%, and $70 \%$ agreement in classification, respectively, among the experts. Thus, these questions were classified in the function domain as well. In addition, questions 9 and 10 showed a $60 \%$ and $55 \%$ agreement, respectively. 
In summary, 10 questions $(1,3,4,5,8,11,18$, 19, 20, and 21) were classified in the same domain as originally proposed in chapter three with $90 \%$ or higher agreement among the experts. On the other hand, questions $2,6,7,9,10,12,13,14,15,16$, and 17 demonstrated less than $90 \%$ agreement among the experts. Also, these questions were not modified nor eliminated for the factor analysis. Content Validity: Factor Analysis (Table 6).

The results of the factor analysis procedures identified five significant factors on the basis of the eingenvalues-greater-than-one rule. Questions 1, $8,9,15,16,17,18$, and 21 were most highly loaded on factor I (Perception domain) with factor loadings or $.72, .74, .67, .77, .87, .87, .54$, and .63, respectively. Further, questions 3, 5, 6, 10, and 13 were most highly loaded on factor II (Function domain) with factor loadings of .60, .70, .83, .72, and .65, respectively. Questions $2,7,19$, and 20 were most highly loaded on factor III (Symptom domain) with factor loadings of $.58, .60, .80$, and .57, respectively. In addition, questions 11 and 12 were most highly loaded on factor IV (Daily Routine 
Table 5

Factor Matrix for the 21 Questions (Variables)

Factors: I II III IV V

\begin{tabular}{|c|c|c|c|c|c|c|}
\hline \multicolumn{7}{|l|}{$\begin{array}{l}\text { Item } \\
\text { Content }\end{array}$} \\
\hline Perception & 1 & .72 & .13 & .26 & .28 & .15 \\
\hline \multirow[t]{7}{*}{ Domain } & 8 & .74 & .19 & .17 & .43 & .16 \\
\hline & 9 & .67 & .07 & .50 & .04 & .37 \\
\hline & 15 & .77 & .26 & .08 & .30 & .03 \\
\hline & 16 & .87 & -.02 & .30 & -.08 & .11 \\
\hline & 17 & .87 & -.02 & .30 & -.08 & .11 \\
\hline & 18 & .54 & .43 & .51 & .16 & .02 \\
\hline & 21 & .63 & .26 & .08 & .36 & -.05 \\
\hline Function & 3 & .57 & .60 & -.03 & -.21 & .05 \\
\hline \multirow[t]{4}{*}{ Domain } & 5 & .21 & .70 & .09 & .33 & -.13 \\
\hline & 6 & .05 & .83 & .16 & -.14 & .04 \\
\hline & 10 & -.10 & .72 & .06 & .15 & .48 \\
\hline & 13 & .21 & .65 & -.02 & .43 & .37 \\
\hline
\end{tabular}


Table 6 (Continued)

Factor Matrix for the 21 Ouestions (Variables)

Factors: I II III IV V

\begin{tabular}{|c|c|c|c|c|c|c|}
\hline & \multicolumn{3}{|c|}{ Content } & & & \\
\hline symptom & 2 & .15 & -.01 & .58 & .05 & .14 \\
\hline \multirow[t]{3}{*}{ Domain } & 7 & .49 & .01 & .60 & .26 & .09 \\
\hline & 19 & .16 & .24 & .80 & .08 & .06 \\
\hline & 20 & .24 & -.01 & .57 & $.4 A$ &.- .86 \\
\hline \multicolumn{7}{|l|}{ Daily Routine } \\
\hline \multicolumn{7}{|l|}{ and } \\
\hline Intellectual & 11 & .07 & -.01 & .35 & .83 & .15 \\
\hline Functions & 12 & .40 & -.40 & -.03 & .56 & .25 \\
\hline \multicolumn{7}{|l|}{ Life } \\
\hline \multicolumn{7}{|l|}{ satistaction } \\
\hline and Sense of & 4 & .47 & .36 & .24 & .12 & .57 \\
\hline พe11-Being & 14 & .24 & .07 & .20 & .16 & .85 \\
\hline
\end{tabular}


and Intellectual Function domain) with factor loadings of .83 and.56, respectively. Finally, questions 4 and 14 most highly loaded on factor $V$ (Life Satisfaction and Sense of Well-Being domain) with factor loadings of .57 and .85 , respectively. Reliability Measurement: Coefficient Alpha.

Coefficient alpha was used to determine the internal consistency of the questions within each identified factor. An alpha coefficient greater than .70 was considered to be indicative of acceptable reliability. Factor I had an alpha coefficient of .93. Factor II, III, IV, and $v$ had alpha coefficients of $.81, .68, .63$, and .76 , respectively.

\section{Summary of Findings}

The results of the factor analysis (content validity measurement) identified five distinct factors rather than three as originally suggested. The five constructs were named as follow: perception domain (factor I), function domain (factor II), symptom domain (factor III), daily routine and intellectual functions (factor IV), and life satisfaction and sense of well-being (factor $v$ ). Further, the results of the factor analysis also 
showed a positive agreement with the original classification as well as the experts for questions $1,8,15,17$ (factor I), 3, 5, 10, 13 (factor II), and $2,19,20$ (factor III), but not for questions 4, $6,7,9,11,12,14,16,18$, and 21 . Several questions, should be rewritten to eliminate ambiguity and then be retested for content validity using factor analysis. The following questions should be rewritten: $6,7,9,16$, and 18, overall, this questionnaire demonstrated poor content validity. Factors I, II, and $V$ had high internal consistency as evidenced by alpha coefficients of $.93, .81$, and .76 , respectively. On the other hand, factors III and IV had Iow alpha coefficients 1.68 and.63, respectively) and hence, moderate reliability. This was perhaps due to the ambiguity of some questions and possibly a close relationship between the function and symptom domains. 


\section{Discussion of Findings}

\section{Factor Analysis}

Factor I showed a fair agreement with the original and subjective evaluation of the questionnaire. Questions 1 and 8 had high agreement among the experts (908) a well as factor loadings of .72 and .74, respectively. Questions 15 and 17 demonstrated less than 908 agreement among the experts. Further, these questions appeared to be related to perception of feelings, such as a sense of health status and well-being. On the other hand, questions 9 and 16 which were originally classified in the runction domain, had fairly high loadings $(.67$ and .87 , respectively) on factor I (perception domain). It appeared that both quastion could in reality have been classified under two domains (function and perception). According to the definition (wenger et al., $1984 \mathrm{a}$ ), perceptions are defined as an individual's view of his or her situation. of particular interest are perceptions of general health status, level of well-being, and satisfaction with life. In contrast, functions include activities involved in dally personal functioning such as 
dressing, eating, meeting basic inaividual needs, and maintaining adequate physical activity. Thus, question 9 (How much energy or vitality do you have? In particular with reference to your exercise program or participation in physical activities.) could have been interpreted as a perception of general health status (i.e., How much energy do you perceive you have?) and/or the ability to perform physical activities (function domain). Similarly, question 16 (How much energy do you have in order to partictpate in your commulty activitios interpreted as a perception of general health status (1.8., How much energy do you perceive you have to participate in your activities?) and/or the ability to participate in social activites (runction domain). Perhaps, if worded differently, these questions could have been classified clearly under one particular domain. Further, guestion 18 and 21 were originaliy classified in the symptom domain with a 958 agreement among the experts. However, question 18 (How often do you reel weak, tired, or latigue to perform your job?) could have possibly been interpreted as one's perception of health status rather than just physical symptoms. 
In sumary, factor I appeared to represent the perception domain of the quality of life spectrum.

Factor II ( function domain) demonstrated a fair agreement with the original and subjective evaluation of the questionnaire. All questions $(3,5,10$, and 13) with the exception of question 6 (How satisfied are you with your sex life?) were originally classified under the function domain. These questions were related mostly to one'g functional capacity within one's job, personal relationship, commity, and social activities. Question 6 , however, could have possibly been interpreted in either domain: perception of feelings (How do you perceive your sex 1ifa?) and/or function domain (Are you satisfied with your ability to perform sex?).

Factor III (symptom domain) had questions which were originally classifled under the symptom domain with the exception or grestion 7 . This guestion, (Do you feel healthy enough to participate in your usual activites?) could have been interpreted in probably all three domains. For example, it could have been interpreted under the runction domain (Can you participate in your usual activities?). Further, this same question could have been interpreted under the perception domain (Do you perceive yourself 
ealthy?). Finally, it could have been interpreted under the symptom domain (Do you feel any physical symptoms?) .

Factor IV contained questions related to one's ability of performing daily personal tasks and the ability to cope with stress (questions 11 and 12 , respectively). Further, these questions were originally classified in the function domain with a $95 \%$ and $80 \%$ agreement among the experts for guestions 11 and 12 , respectively. However, it may be plausible to rewrite questions 11 and 12 so they would fit under the function domain. For instance, question Il could bo rewritten as follows: At home, how often can you perform your usual activities? (1.e., rising, dressing, foding yoursel, maintaining adequate physical activity). Also, question 12 could be rewritten as follows: (At work, how often do Eiressful situations interfare with your job performance?). This factor was named as dally routine and intellectual functions.

Factor V contained questions (4 and 14) related to the degree of satisfaction of one's personal iffe and the degree of one'g interest at work which were originally classified in the perception domain with a $100 \%$ and 608 agreement among the experts, 
respectively. Also, it may be reasonable to rewrite questions 4 and 14 so they would fit under the perception domain. For example, question 4 could be rewritten as follows: (Are you satisfied with your life in general?). Also, question 14 could be rewritten as follows: (At work, how often do you feel satisfied with your job?). This factor was named as life satisfaction and a sense of well-being. In sumary, the results of the factor analysis (content validity measurement) Identified five distinct constructs rather than three as originally proposed. Thus, the five constructs were named as follows: perception domain (factor I), function domain (factor II), aymptom domain (factor III), daily routins and intellectual functions (factor IV), and life satisfaction and sense of well-being (factor V). Further, questions 1 and 8 (factor I); 3 and 5 (factor II): and 19 and 20 (factor III) demonstrated $90 \%$ or higher agreement with the original classification as well as the experts classification. It was suggested that questions 4, 6, 7, 9, 11, 12, 14, 16, and 18 should be rewritten and retested for content validity. Finally, it was concluded that this questionnaire demonstrated poor content validity. 


\section{Reliability measurement}

A coefficient alpha was used to determine the internal consistency of all questions within each identified factor. Factor I showed an alpha coefficient of .93. Factor II and V showed alpha coefficients of .81 and .76, repectively. However, factors III and IV had alpha coefficients of .68 and .63, respectively. These values were considered lower than the acceptable value of $\mathrm{R}$ greater than .70 .

The author believed that the main reason for such low alpha coefficients for factors III and IV were due perhaps to the ambiguity of some questions as discussed above and possibly a close relationship between the function and symptom domains. In summary, factor I, II, and V had high alpha coefficients for the reliability measurement which included questions related to one's perception of feelings (factor I), functional capacity (factor II), and life satisfaction and sense of well-being (factor V). On the other hand, factors III (symptom domain) and IV (Daily Routine and Intellectual functions) did not have high alpha coefficients. 


\section{Conclusions}

Within the limits of this study the following conclusions were made:

(1) The results of the factor analysis (content validity measurement) identified five distinct constructs rather than three as originally proposed. The five constructs were the following: perception domain (factor I), function domain (factor II), symptom domain (factor III), daily routine and intellectual functions (factor IV), and life satisfaction and sense of well-being (factor $v$ ).

(2) The results of the factor analysis (content validity measurement) supported the original classification as well as the experts' classification with a $90 \%$ agreement for questions 1 and 8 (factor I), 3 and 5 (factor II), and 19 and 20 (factor III); but not for questions $4,6,7,9,11,12,13,14$, 16, and 18. It was concluded that this questionnaire demonstrated poor content validity.

(3) Factors I, II, and $V$ had high internal consistency as evidenced by alpha coefficients of $.93, .81$, and .76, respectively. On the other hand, factors III and IV had low alpha coefficients $(.68$ and .63, respectively) and hence reliability, due 
perhaps to the ambiguity of some questions and possibly a close relationship between the function and symptom domains.

\section{Weaknesses of study}

The ambiguity of several questions may have affected the results of the factor analysis used to determine content validity and consequently, the reliability of the Quality of Iife Questionnaire.

\section{Recommendations for Future Research}

Within the limits of this study the following recommendations were made:

(1) Future research should rewrite questions 4, $6,7,9,11,12,14,16$ and 18 , and this retest the questionnaire for content validity.

(2) Future research should use a larger sample of subjects than the sample size used in this study.

(3) Future research with a larger sample size may use a Discriminant Analysis to determine which questions best discriminate between the quality of life factors. 


\section{Summary of Chaoter}

This chapter presented the introduction, analysis of data, summary of findings, discussion of findings, conclusions, weaknesses, and recommendations for future research. 


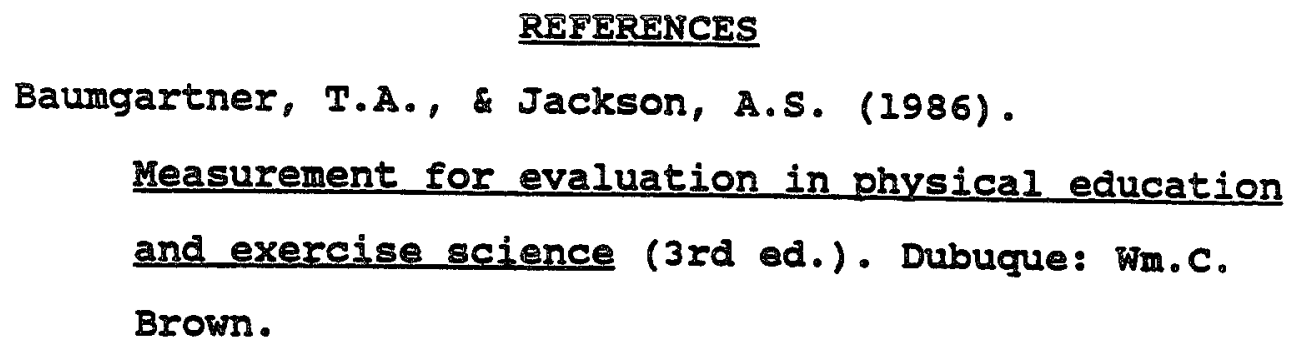

Bulpitt, C.J., Dollery, C.T., Carve, S. (1974). A symptom questionnalre for hypertensive patients. Jounal of chronic Disease, 38, 121-128.

Bulpitt, C.J.. Hoffbrand, B.I., Dollery, c.T. (1976). Psychological features of patients with hypertension attending hospital follow-up clinics. Journal of Psychosomatic Research, 20, 403-410. 
Croog, S.H., Levin, S., Testa, M., Brown, B., Bulpitt, C., Jenkins, E., \& Klerman, G. (1986). The effects of anti-hypertensive therapy on the quality of life. New England Journal of Medicine, $314(26), 1627-1664$.

Deyo, R.A. (1984). Measuring functional outcomes in therapeutic trials for chronic disease. Controlied clinical Trials, 5, 223-240.

Fletcher, A., Bulpitt, C.J. (1985). The treatment of hypertension and guality of life. Quality of Iife and Cardiovascular Care, $1(3), 140-150$.

Haynes, B., Sackett, D.I., Taylor, w., Gibson, E., \& Johnson, A.I. (1978). Increased absenteeism from work after detection and labeling of hypertension patients. New England Journal of Hedicine, 299, $741-744$.

Hyman, D., Kaplan, N. (1985). Treatment of patients with mild hypertension. Hypertension, I(2), 165-170. 
Hypertension detection and follow-up program cooperative group (1979). Five-year findings of the hypertension detection and follow-up program. Jama, 242(23), 2562-2571.

Jachuck, S.J., Brierly, H., \& Jachuck, S. (1982). The effect of hypotensive drugs on the quality of 1ifo. Journal of Royal College of General Practician, 32, 103-105.

Raplan, N.R., Bush, J.W., Berry, C.C. (1976). Health status: Types of validity and the index of well-being. Health Services Research, 11, 478507.

Kaplan, N.M. (1980). Heart disease: A textbook of cardiovascular medicine. In E. Braunwald (Ed.), Systemic Hypertension: Therapy (pp. 2922-2951). Philadelphia: .B. Saunders.

Ridson, M.A. (1971). Personality factors in hyportension. Australian New zesland Journal of Psychiatzy, 5, 139-145. 
Rrauth, J. (1982). Objective measurements of the quality of life. Experentia, 41(supplement), 402-451.

Monk, M. (1981). Blood pressure awareness and psychological well-belng in the health and nutrition examination survey. Clinical Journal of Investigative Medicine, 4, 183-190.

Mossey, J.M. (1981). Psychological consequences of labeling in hypertersives. clintcal Journal of Investigative Medicine, 4 , 201-207.

Najman, J.M., \& Levine, S. (1981). Evaluating the impact of medical care and technologies on the quality of life: A review and critique. social Science and Hedicine, 15, 107-115.

Hornby, A.S. (1975) . Oxford Advanced Iearner'sDictionary of current English (3rd ed.). Iondon: Oxford University press. 
Soghikian, K., Faliick, Funter, E.M., \& Vry, H.K. (1981). The effect of high blood pressure awareness and treatment on emotional well-being. Clinical Journal of Investigative Medicine, 4 , 191-196.

The 1984 report of the joint national committee on detection, evaluation and treatment of high blood pressure (1984). Archives of International Medicine, 144, 1045-1057.

Wenger, N.R., Mattzon, M.E., Furberg, C.D., \& Elinson, J. (1984a). Assessment of quality of life in clinical trials of cardiovascular therapies. In N.R. Wenger, M.E. Mattson, C.D. Furberg, J. Elinson (Eds.), Role of Quality of Life Assessment in Clinical Trails (pp. 67-82). Le Jacq.

Wenger, N.R., Mattson, M.E., Furberg, C.D., \& Elinson, J. (1984b). Assessment of quality of life in clinical trials of cardiovascular therapies. In N.R. Wenger, M.E. Mattson, C.D. Furberg, J. Ellison (Eds.), Selecting a ouality of Iife Assessment Instrument (pp.239-249). Le Jacq. 
Wenger, N.R., Hattson, Hi.E., Furberg, C.D., \& Elinson, J.(1984C). Assessment of quality of life in clinical trials of cardiovascular therapies. In N.R. Wenger, M.E. Mattson, C.D. Furberg, \& J. Elinson (Eds.), Mild Hypertension (pp. 285-295). Le Jacg. 
APPENDIX A

STUDY TO ESTIMATE THE RELIABILITY OF A QUALITY

OF LIFE QUESTIONNAIRE DESIGIED

FOR HYPERTENSIVE PATIENTS

\section{Invitation to Participate}

You are invited to participate in a study investigating the reliability of a quality of life questionnaire designed for hypertensive patients undergoing long-term drug therapy. This study will be conducted in the cooper Clinic Laboratory, in Dallas, TX.

Purpose of the study

The purpose of this study is to estimate the reliability of a guality of life questionnaire for hypertensive patients undergoing long-term drug therapy.

\section{Explanation of Procedures}

\section{Questionnaire completion}

The hypertensive patient's quality of life questionnaire will be given once to all patients in order to test its reliability. Each patient will 
complete one copy of the questionnaire during their blood pressure check visit at the cooper clinic. Also, the patient will be asked not to write their name on the questionnaire. Once completed, all answers will be kept in confidence to ensure proper statistical measurements.

\section{Benefits for participation in the study}

You will benefit frow this study by enhancing the communication between you and your doctor, which in turn will lead to better health care. By knowing how your present medication is affecting your quality of life, proper changes can be made in your treatment, which will best meet your noeds. This questionnaire will also help rany other patients (present and future) that are, or will be undergoing long-term drug therapy for hypertension, as well as help the doctors.

\section{Assurance of confidentiality}

The results of this study may be used for research publication and presentation. Your right to confidentiality will be protected unless your expressed consent is granted prior to the publication and presentation of the data. 
Withdrawal from the study

You may withdraw your consent and discontinue

your participation in this study at any time. you may also decline to answer any questions or items on the quality of life questionnaire.

The questionnaire will be handled by carla Sottovia. If you have any guestions about the study, please feel free to ask. If additional questions come up later, call carla at (214) 960-8557. For questions, coments, or complaints about research subject's rights, contact Dr. Serena standford, Associate Academic Vice President of Graduate studies and Research, at (408) 924-2480.

Consent

By signing this form, you are agreeing:

(1) You decided to participate in this study having read the information provided above.

(2) You understand you can withdraw at any time.

(3) You undexstand that your name will be kept confidential except with your expressed conent. 
signature

Date

Print Name

Signature of Witness

Signature of Investigator 
APPENDIX B

HYPERTENSIVE PATIENT'S QUALITY OF LIFE QUESTIONNAIRE

The enclosed brief questionnaire is designed to be answered by patients on blood pressure medication. The purpose of this questionnaire is to help increase communication between you and your doctor. Better communication leads to better health care.

Please answer the questions as best you can. Your answers will be treated in the strictest confidence.

Thank you very much.

Please answer the following questions by checking oniy one box for each question. Check the statement that comes nearest to what has been true for you during the last four weeks.

1) How are you feeling, in general?

1. In excellent apirits ()

2. In very good spirits ()

3. In good spirits, mostly () 
4. I'm up and down in spirits ()

5. In low spirits, mostly ()

6. In very low spirits ()

2) How often are you bothered by illness, aches, or pains?

1. None of the time ()

2. Rarely ()

3. Occasionaliy ()

4. About half the time ()

5. Almost everyday ()

6. Everyday ()

3) How active are you within the community, and with relatives and friends?

1. Very active ()

2. Usually active ()

3. Occasionaliy active ()

4. Somewhat lese active lately ()

5. Rarely active lately ()

6. Not active at all time ()

4) How satisfied are you with your personal life? 
1. Very satisfied ()

2. Usually satisfied ()

3. Occasionally sacisfied ()

4. Rarely satisfied ()

5. Dissatisfied ()

6. Very dissatisfied ()

5) At work, how often do you have trouble parforming your job?

1. None of the time ()

2. A little of the time ()

3. Some of the time ()

4. A good bit of the time ()

5. Most of the time ()

6. A11 of the time ()

6) How satisfled are you with your sex life?

1. Very satisfied ()

2. Usualiy satisfied ()

3. Occasionally satisfied ()

4. Rarely satisfied ()

5. Dissatisfied ()

6. Very dissatisfied () 
7) Do you feel healthy enough to participate in your usual activities?

1. Yes, I feel healthy enough all the time ()

2. Yes, I feel healthy enough most the time ()

3. Occasionally, I don't feel healthy enough ()

4. No, I rarely feel healthy enough ()

5. Somerimes, I need help to participate in my usual activities ()

6. Most of the tim I reed help to participate in my usual activities ()

8) How often do you feel depressed, down, or unhappy?

1. None of the time ()

2. A 11ttle of the time ()

3. Some of the time ()

4. A good bit of the time ()

5. Most of the time ()

6. All of the time ()

9) How much energy or vitality do you have? (In particular with reference to your 
exercise training program or participation in physical activities.)

1. Very energetic ()

2. Fairly energetic most of the time ()

3. My energy level varies quite a bit ()

4. Generaliy low in energy ()

5. Very low in energy most of the wime ()

6. No energy at all; I feel tired, wors out ()

10) How satisfied are you in your relationships with your spouse and family?

1. Very satisfied ()

2. Usually satisfied ()

3. Occasionally satisfied ()

4. Rarely satisfied ()

5. Dissatisfied ()

6. Very dissatisfied ()

11) At home, how often do you have trouble in performing your usual activities? ( i.e., rising, dressing, feeding yoursele, or maintaining adequate physical activity). 1. None of the time () 2. A little of the time () 
3. Some of the time ()

4. A good bit of the time ()

5. Most of the time ()

6. All of the time ()

12) At work, how often do you have trouble coping with stressful situations?

1. None of the time ()

2. Rarely ()

3. Occasionally ()

4. About half the time ()

5. Almost everyday ()

6. Everyday ()

13) How often does stress interfere in your relationship with your spouse and family?

1. None of the time ()

2. A Iittie of the time ()

3. Some of the time ()

4. good bit of the time ()

5. Most of the tine ()

6. All of the time ()

14) At work, how often do you feel withdrawn, uninterested with your job? 
1. None of the time ()

2. Rarely ()

3. Occasionally ()

4. About half the time ()

5. Almost everyday ()

6. Everyday ()

15) How satisfied axe you in your relationship with your friends?

1. Very satisfied ()

2. Usually satisfled ()

3. Occasionaliy satisfied ()

4. Rarely satisfied ()

5. Dissatisfled ()

6. Very dissatisfied ()

16) How much energy do you have in order to participate in your community activities?

1. Vary anargetic ()

2. Fafrly eriergetic most the time ()

3. My energy level varies quite a bit ()

4. Generally low in energy ()

5. Very low in energy most of the time ()

6. No energy at alI () 
17) At work, how satisfied are you in your relationship with your co-workers?

1. Very satisfied ()

2. Usually satisfied ()

3. Occasionally satisfied ()

4. Rarely satisfied ()

5. Dissatisfied ()

6. Very disatisiad ()

18) How often do you feel weak, tired, or fatigued to perform your job?

1. None of the time ()

2. A little of the time ()

3. Some of the time ()

4. A good bit of the time ()

5. Most of the time ()

6. Everyday ()

19) How orten do you feel weak or exhausted to perfor your regular exercise program?

1. None of the time ()

2. Raxely ()

3. Occasionally ()

4. About half of the time ()

5. Almost everyday () 
6. Everyday ()

20) How often do you feel physically sick to participate in your normal community activities?

1. None of the time ()

2. A little of the time ()

3. Some of the time ()

4. A good bit of the time ()

5. Most of the time ()

6. All of the time ()

21) How often do you have trouble falling to sleep (Insomia)?

1. Hone of the time ()

2. Rarely ()

3. Occasionally ()

4. About half the time ()

5. Almost everyday ()

6. Everyaay () 